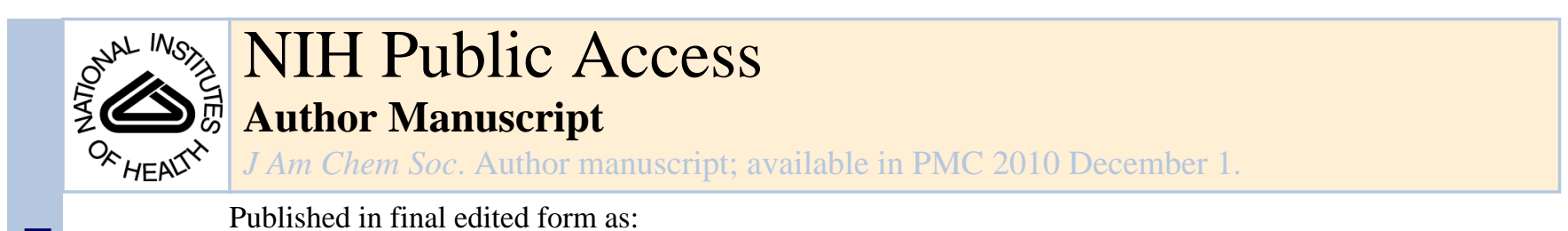

Published in final edited form as:

J Am Chem Soc. 2008 March 26; 130(12): 3736-3737. doi:10.1021/ja710990d.

\title{
Fluorenes and Styrenes by Au(I)-Catalyzed Annulation of Enynes and Alkynes
}

\author{
David J. Gorin, lain D. G. Watson, and F. Dean Toste \\ Department of Chemistry, University of California, Berkeley, California, 94720
}

\begin{abstract}

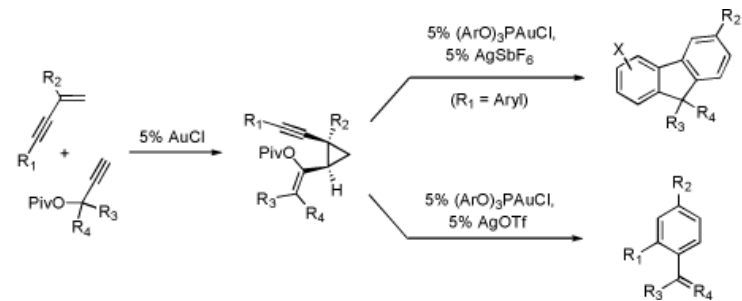

Intermolecular annulation of enynes and propargyl esters to selectively produce styrenes or fluorenes is reported. The divergent arene syntheses involve a Au-catalyzed, two-pot, multi-step process proceeding by cis-diastereoselective cyclopropanation, cycloisomerization, and, finally, annulation or elimination.
\end{abstract}

\begin{abstract}
Metal-catalyzed cycloaddition reactions provide attractive and efficient methods for the synthesis of arenes, although regioselectivity presents a major challenge for intermolecular reactions. 1 The synthesis of polysubstituted benzenes by the $[2+2+2]$ cyclotrimerization of alkynes $^{2}$ has been extensively studied, as has the Pd-catalyzed [4+2] cycloaddition of enynes and activated alkynes. 3 We report herein a mechanistically distinct intermolecular annulation of enynes and alkynes to produce multiply substituted arenes (eq 1); styrene or fluorene products can be selectively accessed by judicious choice of reaction conditions.
\end{abstract}

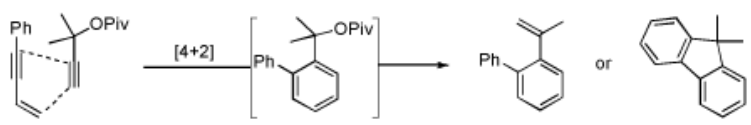

Given the synthetic utility of vinyl cyclopropanes, 4 we anticipated that alkynyl cyclopropanes derived from the cyclopropanation of 1,3-enynes would provide similar opportunities for organic synthesis. ${ }^{5}$ In light of our previous work employing propargyl esters as carbene precursors in $\mathrm{Au}(\mathrm{I})$-catalyzed cyclopropanation reactions of olefins, ${ }^{6}, 7$ the reaction of $\mathbf{1}$ with enyne $\mathbf{2}$ was investigated. ${ }^{8}$

Initially, treatment of $\mathbf{1}$ and $\mathbf{2}$ with a cationic phosphinegold(I) complex resulted in a mixture of products, including styrene $\mathbf{3}$, fluorene $\mathbf{4}$, and cyclopropane trans-5 (eq 2). The

fdtoste@berkeley.edu

Supporting Information Available Experimental procedures and compound characterization data. This material is available free of charges at http://pubs.acs.org 
unexpected products $\mathbf{3}$ and $\mathbf{4}$ were intriguing; $\mathbf{3}$ formally results from a completely regioselective [4+2] cross-dimerization of two different enynes, while compounds such as $\mathbf{4}$ are of interest due to the blue-light emitting properties of polyfluorenes. ${ }^{9,10}$

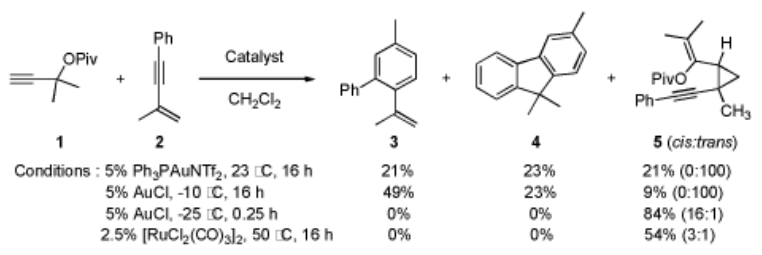

Since cyclopropane $\mathbf{5}$ was obtained exclusively as the trans-diastereomer, we hypothesized that $\mathbf{3}$ and $\mathbf{4}$ arose from the cis-diastereomer. Therefore, we were pleased to find that the less reactive $\mathrm{AuCl}$ cleanly catalyzed the synthesis of cyclopropane 5 with high cisdiastereoselectivity and complete regioselectivity. With ready access to $c i s-\mathbf{5}$, we next investigated its transformation to $\mathbf{3}$ and $\mathbf{4}$.

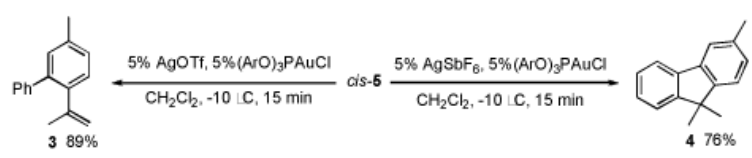

Gratifyingly, either compound could be selectively prepared simply by changing the silver salt co-catalyst in conjunction with triarylphosphitegold(I) chloride $(\mathrm{Ar}=2,4$-di-tertbutylphenyl). ${ }^{11,} 12$ Thus, reaction of $c i s-\mathbf{5}$ with the Au complex and AgOTf provided $\mathbf{3}$ in $89 \%$ yield, while the reaction with $\mathrm{AgSbF}_{6}$ under otherwise identical conditions provided 4 in $76 \%$ yield (eq 3 ). ${ }^{13}$

The substrate scope of the two-step, divergent syntheses of fluorenes and styrenes was investigated with other enynes (Table 1). ${ }^{14}$ Aryl enynes with a variety of substitution patterns and functional groups were tolerated, demonstrating the power of this method to prepare multiply substituted arenes from simple starting materials (entries 1-13). Moreover, both electron-rich and electron-poor enynes 14 and 18 undergo the cyclopropanation and arene syntheses; however, commensurate with the expected nucleophilicities of the aryl group, they demonstrated diametric preferences for styrenes versus fluorene formation (entries 3,4). Alkyl-substituted enynes are also tolerated in both the cyclopropanation and annulation steps (entries 14-16).

The carbene precursor was also varied (Table 2). The pivaloate ester provided the best selectivity in differentiating between the styrene and fluorene pathways (entries 1-3). [9,9]Dibutyl-substituted fluorene $\mathbf{8 2}$ was prepared (entry 6); such hydrophobic solubilizing groups are often found in fluorenes designed for subsequent polymerization. Additionally, the use of unsymmetrical pivaloate 83 readily provided 85 or 86 (entries 7).

A mechanism accounting for the observed products begins with the formation of $\mathbf{5}$ by intermolecular cyclopropanation of enyne $\mathbf{2}$ via the gold carbenoid produced from rearrangement of propargyl ester $\mathbf{1}$. Following coordination of the cationic gold catalyst to the resulting alkyne, the pendant olefin can participate in either a 5-endo-dig or 6-endo-dig cyclization (Scheme 1). When tertiary propargyl esters are employed in the gold-catalyzed 
annulation, the 5-endo-dig cyclization to generate tertiary carbocation $\mathbf{8 7}$ dominates. Subsequent migration of the pivaloyloxy group gives allylic cation $\mathbf{8 8}$ that may be further stabilized by delocalization of the charge onto gold. Cyclopropyl ring opening via a pentadienyl cation leads to 89 , which is most likely converted to 3 and $\mathbf{4}$ by $\mathrm{E} 1$ and $\mathrm{S}_{\mathrm{N}} 1$ mechanisms, respectively. ${ }^{15,16}$

Use of secondary propargyl pivaloate 90 diverted the reaction pathway towards the 6-endodig cyclization and formation of cycloheptatriene 92 (eq 4). Selectivity for the 5-endo-dig pathway could be partially restored using $\mathbf{9 4}$, which predominantly provided the fluorene $\mathbf{9 7}$, suggesting that, for trisubstituted olefins, electronic factors govern the regioselectivity of the cycloisomerization.

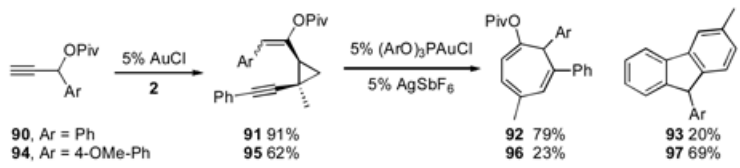

In conclusion, readily available enynes and propargyl esters may be selectively transformed into styrenes or fluorenes under catalyst control via two new Au-catalyzed processes. Synthesized by a rarely investigated, highly selective cyclopropanation of 1,3 enynes, cisvinyl-alkynyl-cyclopropanes undergo a novel cycloisomerization reaction, the outcome of which may be controlled simply through choice of catalyst counterion.

\section{Supplementary Material}

Refer to Web version on PubMed Central for supplementary material.

\section{Acknowledgments}

We gratefully acknowledge NIHGMS (RO1 GM073932), Merck Research Laboratories, Bristol-Myers Squibb, Amgen Inc., and Novartis for funding. D.J.G. thanks the ACS Organic Division (Merck) and Bristol Myers-Squibb for predoctoral fellowships. I.D.G.W. thanks NSERC for a postdoctoral fellowship.

\section{References}

1. For a review, see: (a) Saito S, Yamamoto Y. Chem. Rev 2000;100:2901. [PubMed: 11749309] Intramolecular annulation of enynes and alkynes: (b) Dunetz JR, Danheiser RL. J. Am. Chem. Soc 2005;127:5776. [PubMed: 15839661] (c) Danheiser RL, Gould AE, de la Pradilla RF, Helgason AL. J. Org. Chem 1994;59:5514. Intramolecular annulation of arene-ynes and alkynes: (d) Lian J-J, Chen P-C, Lin Y-P, Ting H-C, Liu R-S. J. Am. Chem. Soc 2006;128:11372. [PubMed: 16939258] (e) Rodriguez D, Martinez-Esperon MF, Navarro-Vazquez A, Castedo L, Dominguez D, Saa C. J. Org. Chem 2004;69:3842. [PubMed: 15153017]

2. (a) Agenet N, Gandon V, Vollhardt KPC, Malacria M, Aubert C. J. Am. Chem. Soc 2007;129:8860. [PubMed: 17585766] (b) Chopade PR, Louie J. Adv. Synth. Catal 2006;348:2307.

3. (a) Rubina M, Conley M, Gevorgyan V. J. Am. Chem. Soc 2006;128:5818. [PubMed: 16637651]

(b) Saito S, Salter MM, Gevorgyan V, Tsuboya N, Tando K, Yamamoto Y. J. Am. Chem. Soc 1996;118:3970. (c) Gevorgyan V, Yamamoto Y. J. Organomet. Chem 1999;576:232.

4. Rubin M, Rubina M, Gevorgyan V. Chem. Rev 2007;107:3117. [PubMed: 17622181]

5. Cyclopropanations of enynes are surprisingly undeveloped. Cyclopropanation with diazo-derived carbenes: (a) Gmyzina RN, D'yakonov IA, Danilkina LP. Zhur. Obshch. Khimii 1970;6:2168. (b) Shapiro EA, Romanova TN, Dolgii IE, Nefedov OM. Izv. Akadem. Nauk SSSR, Seriya 
Khimicheskaya 1985;11:2535. (c) Kretschik O, Nieger M, Dotz KH. Chem. Ber 1995;128:987. Simmons-Smith: (d) Du H, Long J, Shi Y. Org. Lett 2006;8:2827. [PubMed: 16774267]

6. (a) Gorin DJ, Dube P, Toste FD. J. Am. Chem. Soc 2006;128:14480. [PubMed: 17090030] (b) Johansson MJ, Gorin DJ, Staben ST, Toste FD. J. Am. Chem. Soc 2005;127:18002. [PubMed: 16366541] (c) Shi X, Gorin DJ, Toste FD. J. Am. Chem. Soc 2005; 127:5802. [PubMed: 15839674] (d) Lopez S, Herrero-Gomez E, Perez-Galan P, Nieto-Oberhuber C, Echavarren AM. Angew. Chem. Int. Ed 2006;45:6029.

7. (a) Miki K, Ohe K, Uemura S. Tetrahedron Lett 2003;44:2019. (b) Miki K, Ohe K, Uemura S. J. Org. Chem 2003;68:8505. [PubMed: 14575478] (c) Ikeda Y, Murai M, Abo T, Miki K, Ohe K. Tetrahedron Lett 2007;48:6651.

8. For recent reviews of gold-catalyzed reactions, see: (a) Jimenez-Nunez E, Echavarren AM. Chem. Commun 2007:333. (b) Gorin DJ, Toste FD. Nature 2007;446:395. [PubMed: 17377576] (c) Furstner A, Davies PW. Angew. Chem. Int. Ed 2007;46:3410.

9. (a) Neher D. Macromol. Rapid Commun 2001;22:1365. (b) Scherf U, List E. Adv. Mater 2002;14:477. (c) Leclerc M. J. Polym Sci. A: Polym. Chem 2001;39:2867.

10. The synthesis of substituted fluorenes is generally accomplished by [9,9]-dialkylation of fluorene followed by [2,7]-dibromination and subsequent functionalization. See, for example: Tsuie B, Reddinger JL, Sotzing GA, Soloducho J, Katritzky AR, Reynolds JR. J. Mater. Chem 1999;9:2189.

11. For [3,3] rearrangements of cis-vinyl-alkynyl-cyclopropanes, see: metal-mediated: (a) Ohe K, Yokoi T, Miki K, Nishino F, Uemura S. J. Am. Chem. Soc 2002;124:526. [PubMed: 11804476] Thermal: (b) Dolbier WR Jr. Garza OT, Al-Sader BH. J. Am. Chem. Soc 1975;97:5038.

12. For Au-catalyzed benzannulations, see: (a) Hashmi ASK, Frost TM, Bats JW. J. Am. Chem. Soc 2000;122:11553. (b) Dankwardt JW. Tetrahedron Lett 2001;42:5809. (c) Asao N, Takahashi K, Lee S, Kasahara T, Yamamoto Y. J. Am. Chem. Soc 2002;124:12650. [PubMed: 12392398] (d) Asao N. Synlett 2006;11:1645. (e) Zhao J, Hughes CO, Toste FD. J. Am. Chem. Soc 2006;128:7436. [PubMed: 16756286]

13. Other phosphine catalysts provided lower selectivity. For example, treatment of cis-5 with $\mathrm{PPh}_{3} \mathrm{AuCl} / \mathrm{AgSbF}_{6}$ resulted in $63 \% 4$ and $34 \% 3$.

14. Optimization of the one-pot synthesis produced $\mathbf{4}$ in lower yield from $\mathbf{1}$ and $\mathbf{2}$. See supporting information.

15. 89 was isolated and resubjected to the reaction conditions with and without the addition of triarylphosphitegold(I)chloride to afford the expected products, suggesting the possibility for silver or acid catalysis in the final step. Control experiments indicate that neither AgOTf nor HOTf catalyze the cycloisomerization of $\mathbf{5}$. See Supporting Information.

16. Further experiments (see supporting information) indicate that 3 readily isomerizes to 4 under strongly acidic conditions. A deuterium-labeling experiment suggested that this is not a major pathway for the formation of $\mathbf{4}$ under our reaction conditions:

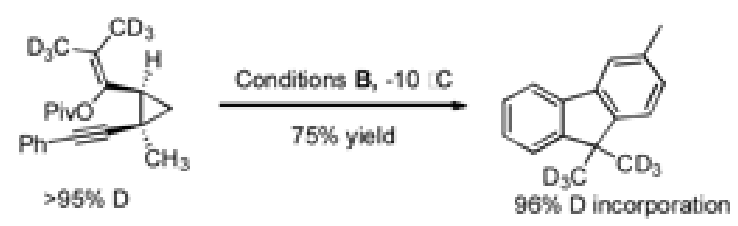




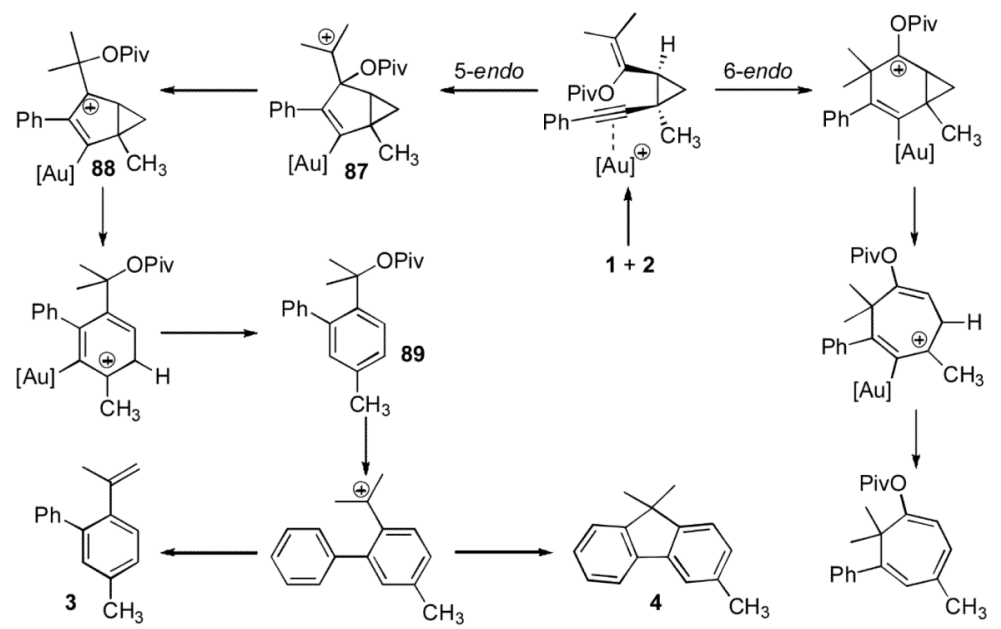

Scheme 1.

Proposed Mechanism for the Formation of $\mathbf{3}$ and $\mathbf{4}$. 


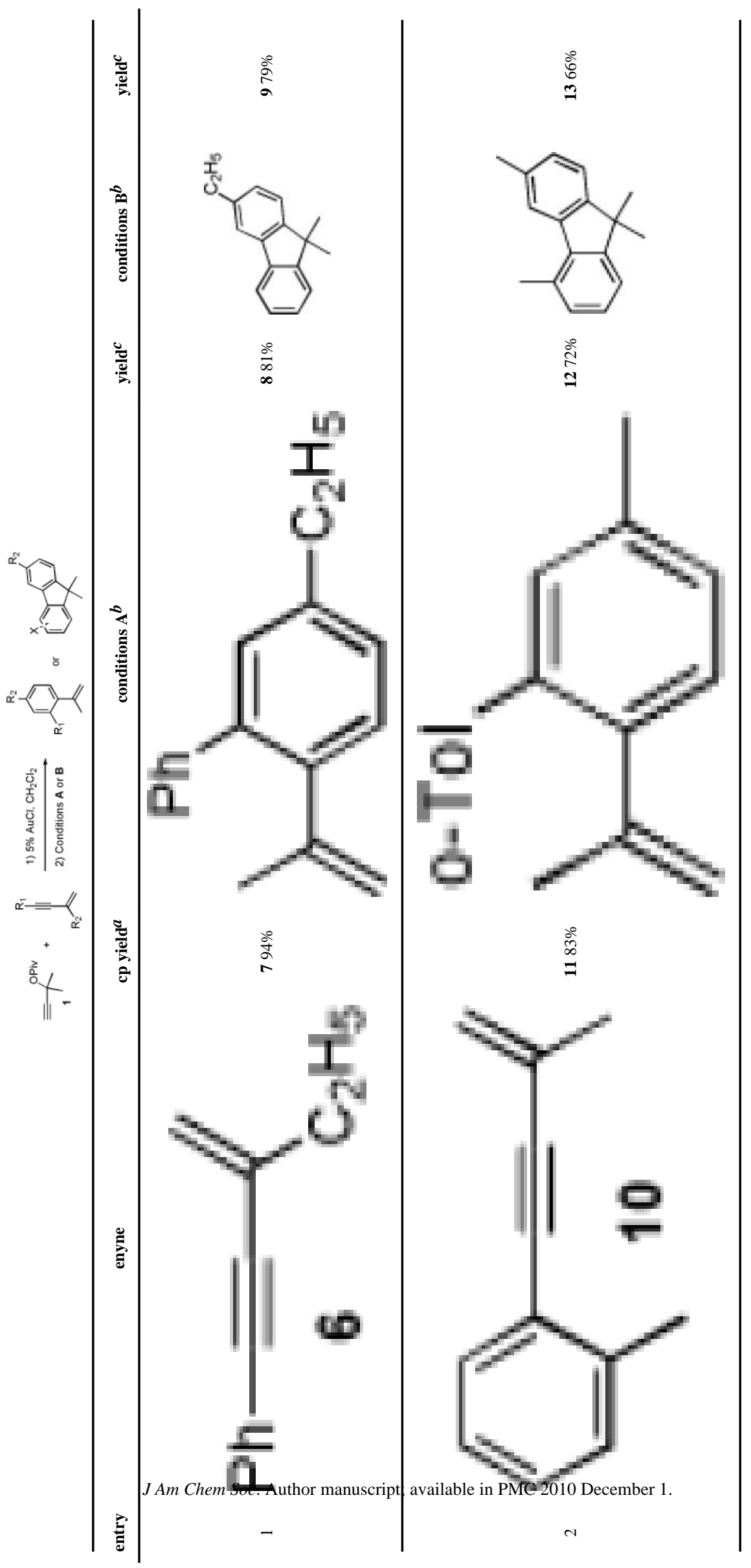




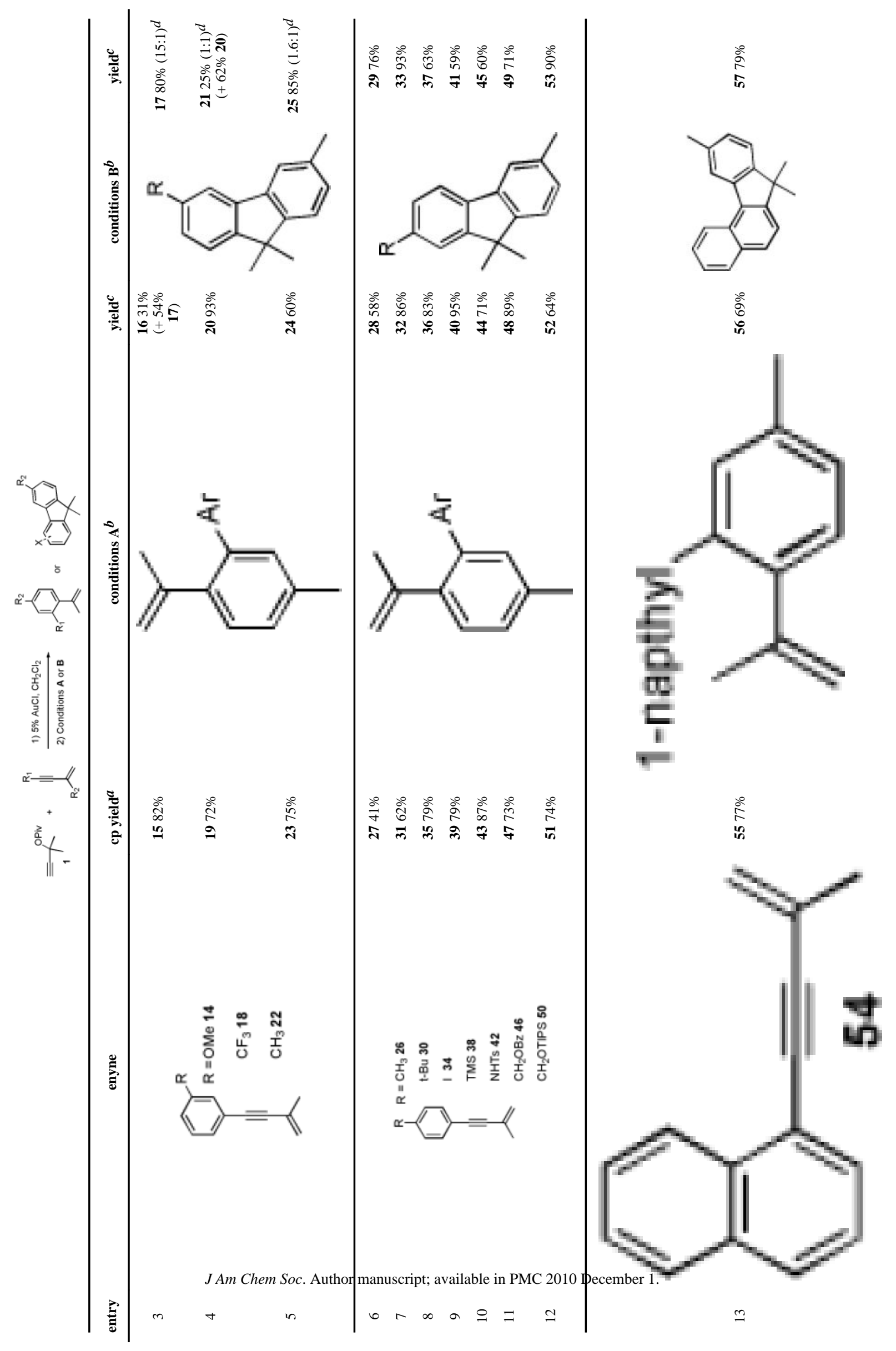




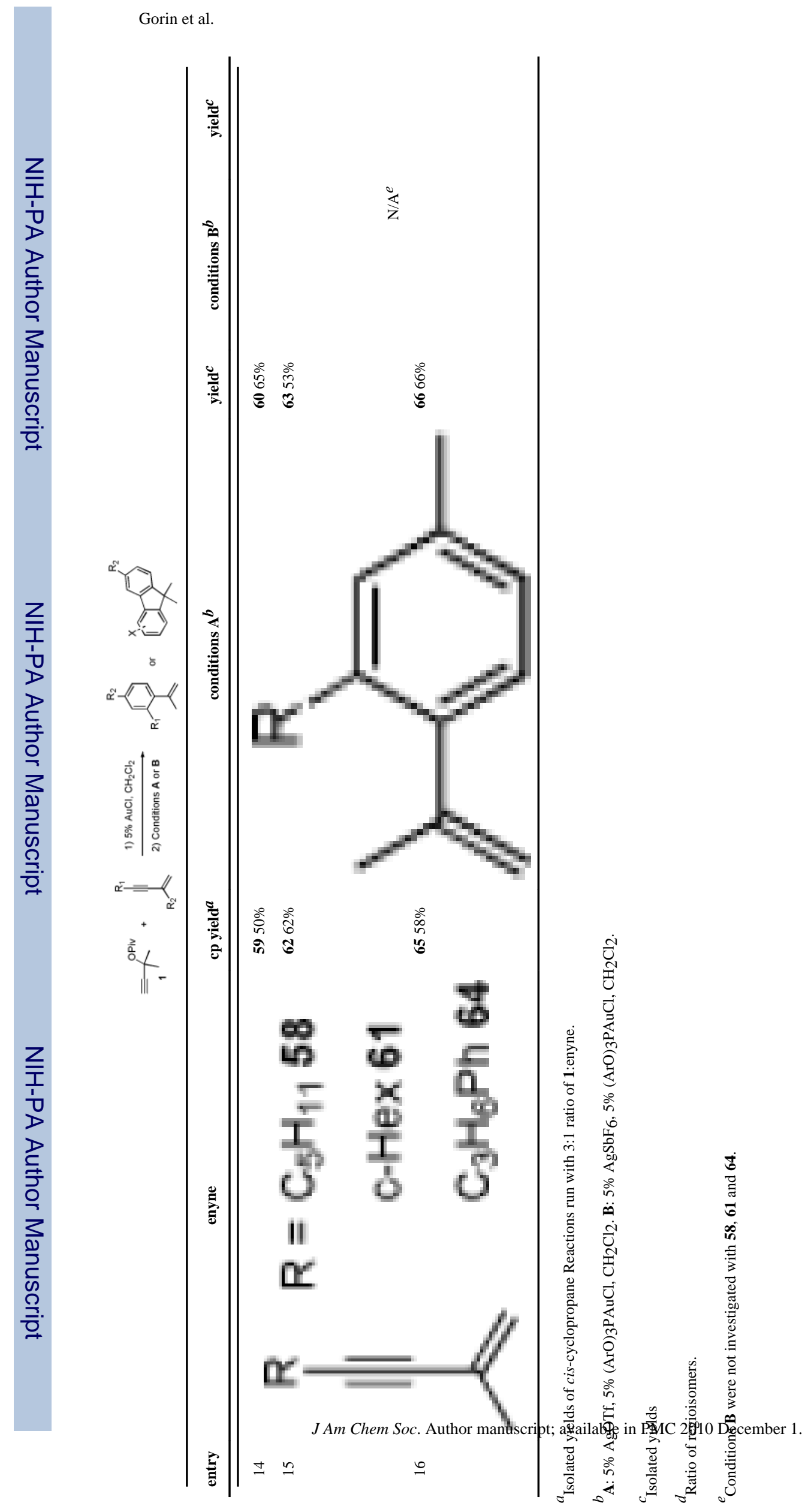




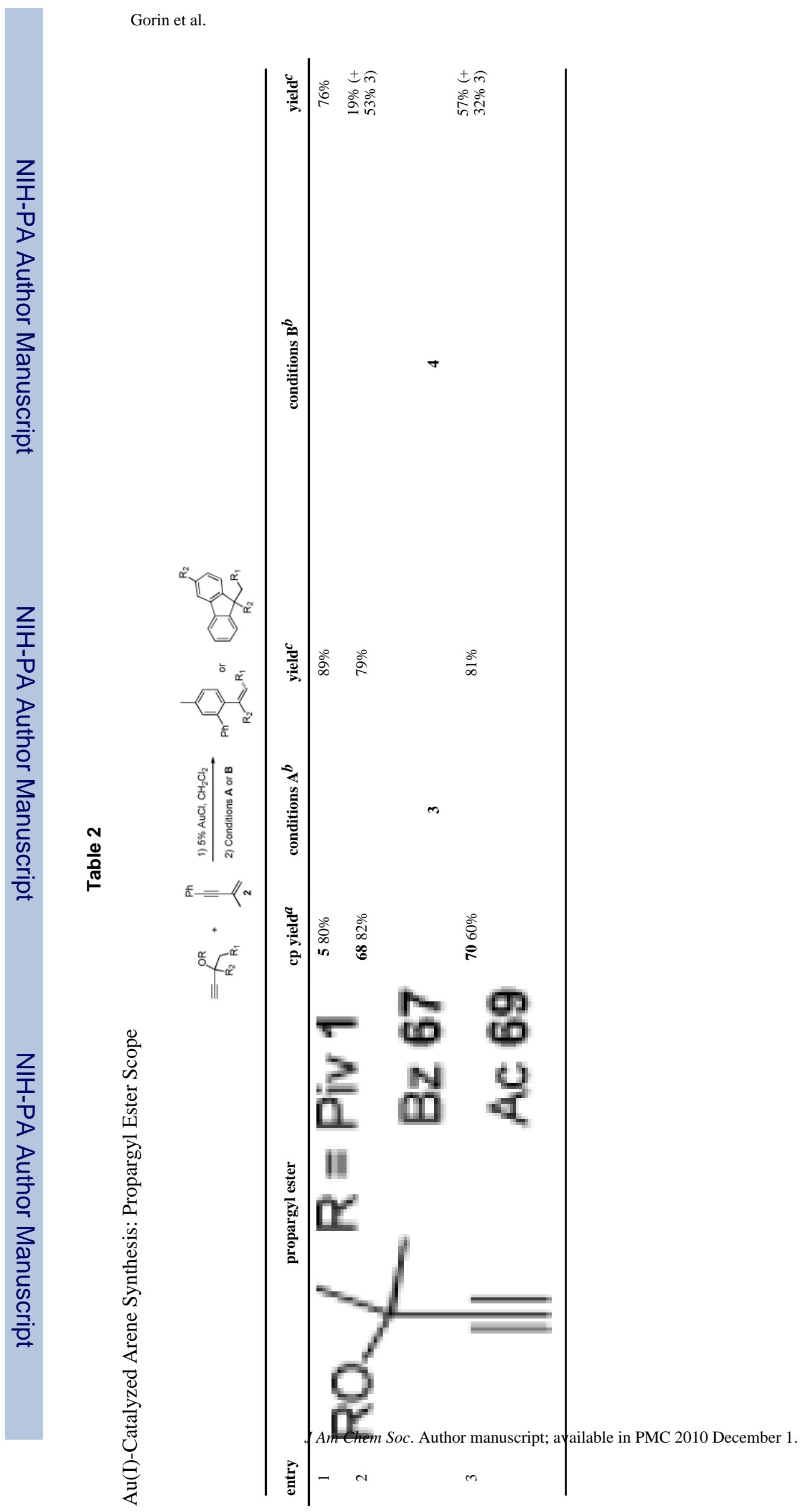




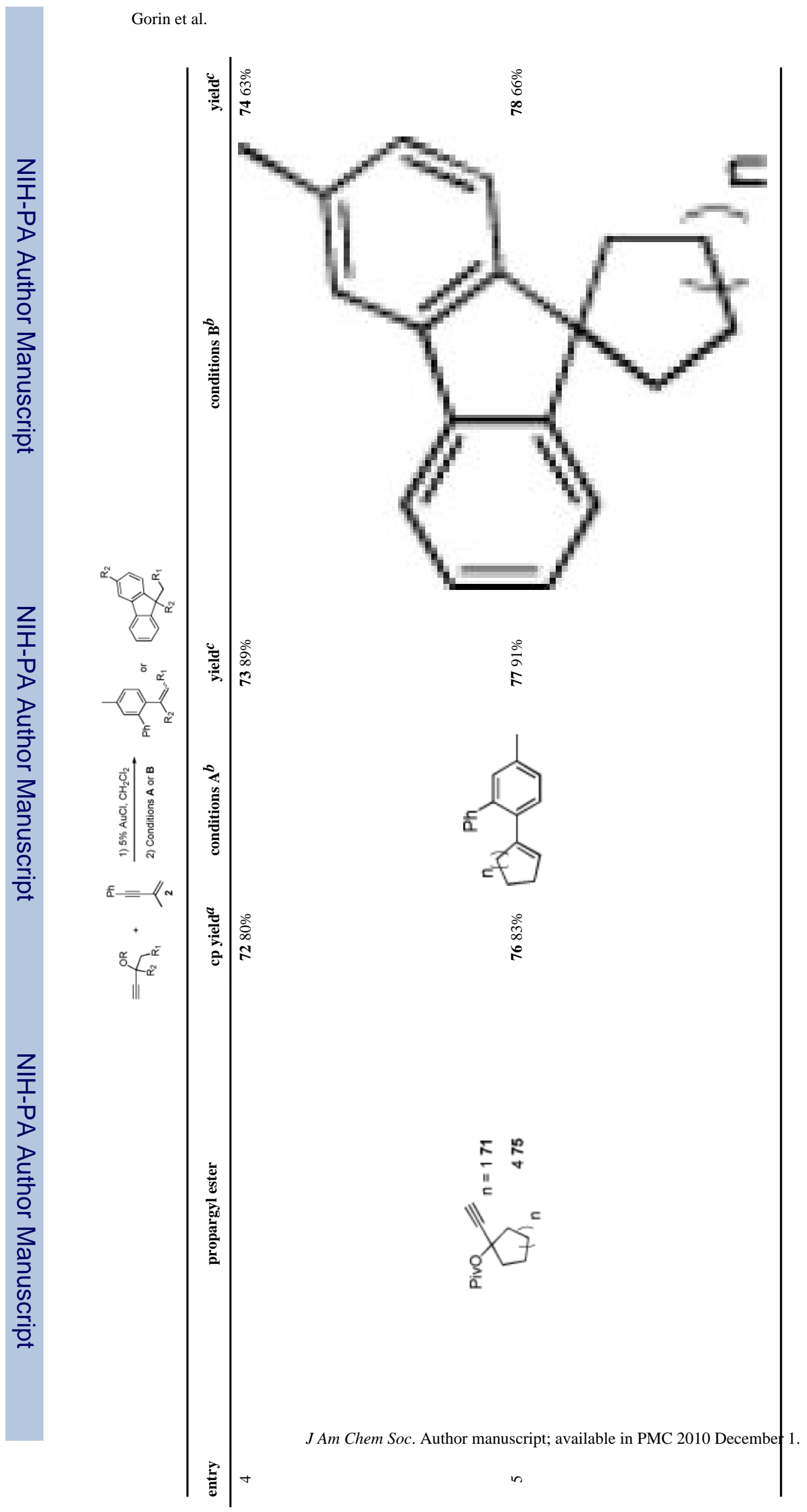

Page 10 


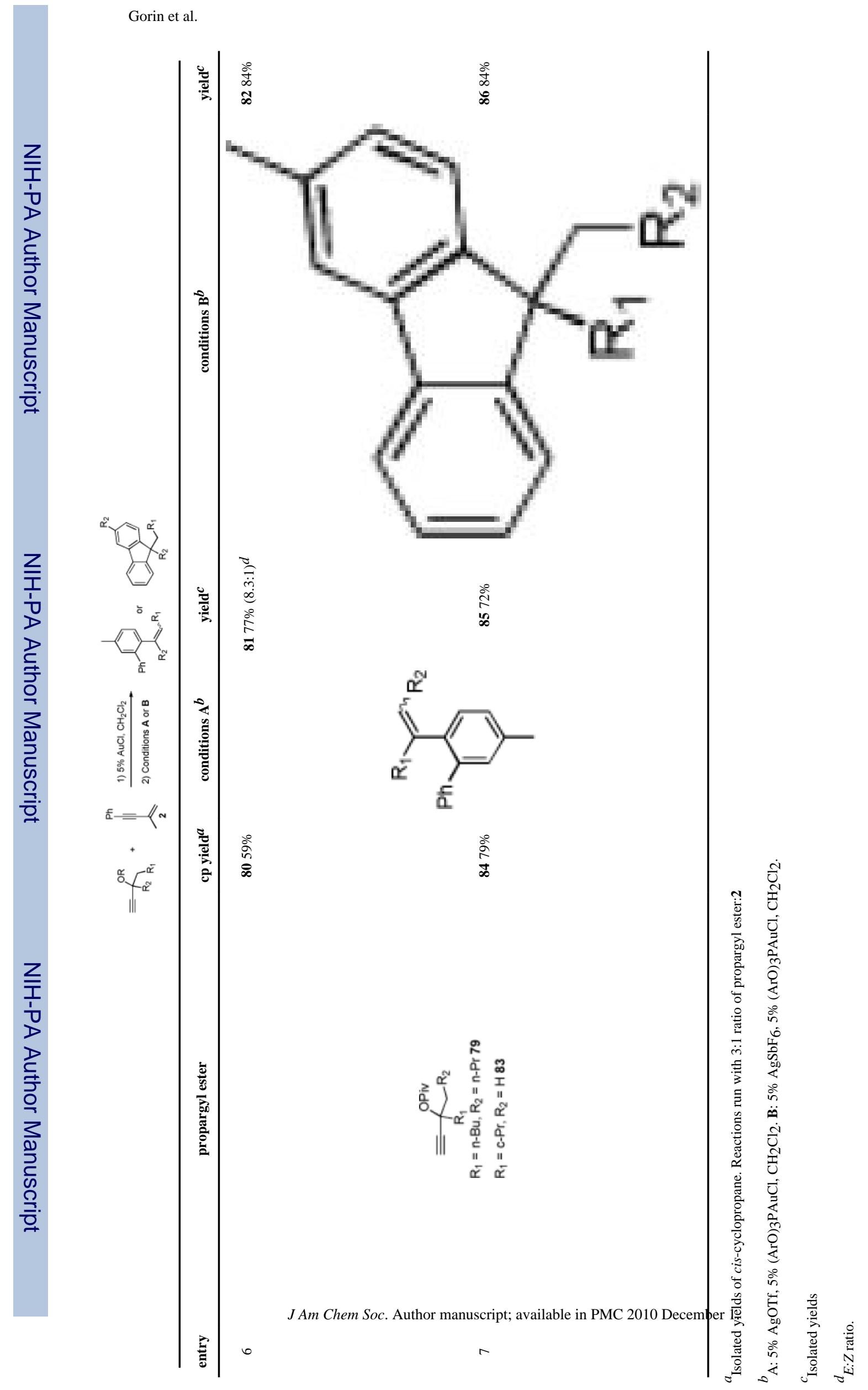

